\title{
Contribution of agricultural produce spice Zingiber officinale to a sustainable food system: green extraction and stability study of antioxidant compounds
}

https://doi.org/10.1515/opag-2018-0036

received November 13, 2017; accepted July 5, 2018

\begin{abstract}
The presentstudy has focused on the extraction and utilization of antioxidant compounds from the agricultural produce Zingiber officinale for its sustainable use in terms of stabilizing food from oxidation. Two extraction methods, traditional soxhlet and green supercritical $\mathrm{CO}_{2}\left(\mathrm{SC}_{-} \mathrm{CO}_{2}\right)$, were used to compare yields of antioxidant (6-gingerol) rich extracts. For the $\mathrm{SC}-\mathrm{CO}_{2}$ method, operating parameters including pressure (10000-20000 $\mathrm{kPa}$ ), temperature (30$\left.40^{\circ} \mathrm{C}\right)$ and $\mathrm{CO}_{2}$ flow rate $(5-20 \mathrm{~g} / \mathrm{min}$.) were optimized to get maximum recovery of [6]-gingerol rich extracts. The results of the extraction study revealed that ginger extract collected after soxhlet extraction (GE1) gives more yield (3.85\%) than the extract (2.41\%) collected after SC-CO ${ }_{2}$ extraction (GE2) at an optimum condition of $20000 \mathrm{kPa}$ pressure, $40^{\circ} \mathrm{C}$ temperature and $20 \mathrm{~g} / \mathrm{min}$. flow rate. Contrarily, the yield of [6]-gingerol was found to be greater in GE2 (389 mg/g) than GE1. Total phenol (TPC) and flavonoid (TFC) content of GE1 and GE2 were measured against equivalent concentrations of gallic acid and quercetin. TPC and TFC of GE1 show slightly higher values (38.50 mg GAE/g, $5.62 \mathrm{mg} \mathrm{QE} / \mathrm{g}$ ) than GE2. At the concentration of $3000 \mu \mathrm{g} / \mathrm{mL}$, DPPH percent inhibition activity of GE1 was again higher (up to 94\%) than GE2 (up to $82 \%$ ). Stability study result of both GE1 and GE2 revealed on thebasis of antioxidantindices, showed desirableantioxidant index by stabilizing all three experimented oils and also found to be comparable with synthetic antioxidants (BHA, BHT). Therefore, it could be concluded that [6]-gingerol rich
\end{abstract}

\footnotetext{
*Corresponding author: Swapnil G. Jaiswal, Supercritical Fluid Extraction Laboratory, Centre for Rural Development and Technology, Indian Institute of Technology Delhi, New Delhi, India-110016, Email: swpnljaiswal320@gmail.com

Satyanarayan Naik, Supercritical Fluid Extraction Laboratory, Centre for Rural Development and Technology, Indian Institute of Technology Delhi, New Delhi, India-110016
}

extracts from the $\mathrm{SC}-\mathrm{CO}_{2}$ method have comparable phenol flavonoid, antioxidant and stability potential as those found in ginger extracts from the traditional soxhlet method.

Keywords: Zingiber officinale spice, Supercritical fluid extraction, Edible oils, Antioxidant study, Rancimat

\section{Abbreviations}

$\mathrm{SC}-\mathrm{CO}_{2}$ : Supercritical $\mathrm{CO}_{2}$ GE1: Ginger extract collected after soxhlet extraction GE2: Ginger extract collected after SC- $\mathrm{CO}_{2}$ extraction TPC: Total phenol content

TFC: Total flavonoid content

HPLC: High performance liquid chromatography AI: Antioxidant index

\section{Introduction}

India is the land of spices, producing over 50 commercial spices in a range of geographic conditions. According to information provided by the Spice Board of India, chilli, followed by garlic, turmeric, ginger, coriander, tamarind, cumin, fenugreek, fennel, pepper and ajwain are the major types of spices produced. In the financial year of 2016-17, a marked growth was noted in the export trade of spices, and the Spice Board of India recorded a trade value of US $\$ 2.633$ billion for the export of 947,790 tons of spices and their products.

Zingiber officinale (ginger), a member of the Zingiberaceae family, is widely grown in the southern, central and north-eastern part of India. Approximately $700,000-800,000$ tons of ginger are produced annually, out of which approximately 25,000 tons are exported 
annually in its raw form. The remaining ginger is processed in the preparation of different food products or utilized by different food or pharmaceutical industries. Ginger is a daily used kitchen spice which enhances the flavour of cooked food, and is also used as flavouring and preservative agent in different products such as flavoured beverages (tea, wine, sugar cane juice, soups), paste (pickle, chutney, sauces, jams), crystallized ginger candies, bread incorporating ginger, fresh ginger slices preserved in syrups and ginger powder in daily cooking and traditional sweet dishes (Anonymous 1976; Anonymous 2003). Apart from food, ginger and its extracts (volatile oil and oleoresin) have numerous applications in medicine, due to their valuable phytochemical profile containing pungent aromatic compounds such as monoterpenoids, ses-quiterrpenoids and non-volatile pungent compounds (Butt and Sultan 2011). Scientifically, it has been proven that gingerols and shogaols are the major pungent biomarkers associated with numerous biological activities including: antioxidant, anticancer, antimicrobial, antifungal, antidiabetic, antiinflammatory, anti-allergic, anti-obesity,anti-nausea, anti-gastric, immune modulatory, hepatoprotective, renoprotective and protective against cardiac disorders (Semwal et al. 2015). The antioxidant and protective effects of ginger spice and its extracts in the preservation of food against oxidative stress have been reported in several studies, which put forth its applicability as a natural antioxidant in the shelf-life enhancement of food materials (Rehman et al. 2003; Zhang et al. 2009; Kumolu-Johnson and Ndimele 2011; Turgay and Esen 2015; Maizura et al. 2016).

Moreover, spices and herbs (black pepper, ginger, turmeric, rosemary and oregano) are reported to have good antioxidant potential and have been suggested as alternatives to some synthetic antioxidants (BHT) which have their origin in petroleum (Redondo-Cuevas et al. 2017). Commercial synthetic antioxidants (BHA, BHT and TBHQ) have a permissible limit to their usage; over this limit they have been found to be hazardous (carcinogenic or liver swelling activities) to human health (Martin and Gilbert 1968; Ito et al. 1986). Therefore, the public is moving towards safer choices, demanding that food products be made from natural resources or contain natural additives/antioxidants. Subsequently pressure on researchers and the food industry to extract natural antioxidants from natural resources in order to help increase the shelf life of food products prone to oxidation has increased.
For a very long time, we have used the solvent extraction technique to extract resinous compounds from plant matrices. But this technique has not been useful to extract some groups of compounds or thermally labile antioxidant compounds by using a single solvent. Moreover, it also requires long extraction times, huge amounts of solvent for extraction, and the chances of solvent residue in the final extract may remain after extraction. Therefore, green extraction techniques with more viable solvents have been developed, resulting in reduced extraction times and the recovery of targeted compounds. SC- $\mathrm{CO}_{2}$ extraction is a useful green extraction technique, which is based on the use of the environment friendly, and generally regarded as safe, solvent $\mathrm{CO}_{2}$ for the extraction of plant based bioactive compounds required for food applications (Vardanega et al. 2015). By use of this technique, the chances of obtaining a solvent free end product at low operating temperatures have increased, and the issues of thermal degradation of antioxidant compounds are resolved (Gomez et al. 1996). Recently, Mesomo et al. (2013) compared the antibacterial activity and chemical profile of ginger extracts obtained by both the supercritical and hydrodistillation method. The results of this study revealed that ginger extracts from the supercritical method exhibited higher antibacterial activity than the extracts obtained by the hydro-distillation method. In a different study, Salea et al. (2017) optimized the supercritical fluid extraction process for the ginger antioxidant compound [6]-gingerol in the laboratory as well as at a commercial scale. The results of this study revealed that a pressure of $15,000 \mathrm{kPa}$, temperature of $35^{\circ} \mathrm{C}$ and a rate of $15 \mathrm{~g} / \mathrm{min}$. were the optimum extraction conditions for [6]-gingerol resulting in yield of $20 \%$ (laboratory scale) and $18 \%$ (commercial scale).

The main aim of the present study was to extract antioxidant rich ginger extract from a north-eastern ginger variety using the $\mathrm{SC}-\mathrm{CO}_{2}$ extraction method. The traditional soxhlet method, using ethanol as an extraction solvent, was also used to extract ginger oleoresin and to compare the yield of both methods in terms of oleoresin and antioxidant concentration. Another objective of the present study was to check the applicability of extracted ginger extracts in terms of stabilizing edible oils which are prone to oxidation. A comparative stability study of both soxhlet and SC- $\mathrm{CO}_{2}$ extracts of ginger were done with synthetic antioxidants (BHA, BHT and TBHQ), in order to measure the effectiveness of antioxidants in three edible oils (Linseed, sunflower and peanut). 


\section{Materials and Methods}

\subsection{Collection of spice sample, chemicals and reagents}

Rhizomes of fresh ginger were collected in January from local agricultural land in the state of Sikkim. Manual washing and slicing of ginger was carried out to air dry the sliced ginger under a controlled temperature $\left(40^{\circ} \mathrm{C}\right)$ for 36 hours. The dried ginger slices in the form of flakes were powdered with grinder and packed in airtight plastic pouches until further extraction.

Experimental solvents viz. methanol, ethanol, hexane, acetonitrile and acetic acid were purchased from MERCK. The powdered chemicals, sodium acetate, anhydrous sodium sulphate, anhydrous sodium carbonate and aluminium chloride were purchased from CDH FINE CHEMICALS. Antioxidant standard, [6]-gingerol and chemical reagents (1, 1-diphenyl-2-picryhydrazyl radical and Folin-Ciocalteu phenol reagent) were obtained from CHROMADEX and SIGMA respectively. The required synthetic antioxidants for the stability study, butylated hydroxyanisole (BHA), butylated hydroxytoluene (BHT) and tert-butyl hydroquinone (TBHQ) were procured from MERCK and ACROS ORGANICS. LASER GASES provided cylinders of liquid $\mathrm{CO}_{2}$ with a purity of $99.99 \%$. Milli-Q grade water was used for all experimental and analytical procedures.

\subsection{Extraction procedures}

\subsubsection{Solvent extraction}

A soxhlet apparatus with ethanol as extraction solvent was used for the extraction of the oleoresin part of powdered ginger samples. Using a 1:10 ratio of sample and solvent in the soxhlet assembly, extraction was carried out at the boiling temperature of the solvent over 8 hours and finally concentrated in rotary evaporator. The yield of oleoresin was calculated on a percent weight basis.

\subsubsection{SC- $\mathrm{CO}_{2}$ extraction}

An imported Supercritical fluid extraction unit (Thar SFE, Pittsburgh, USA) containing both extraction and product collector vessel of $500 \mathrm{~mL}$ capacity was used for SC- $\mathrm{CO}_{2}$ extraction. The availability of advanced key features (automated/manual back pressure regulator, heat exchangers, high pressure pump, chiller and PLC operated system) for the optimization of process parameters (pressure, temperature and $\mathrm{CO}_{2}$ flow rate) was the reason for using this instrument for the extraction of the targeted biologically active compounds from ginger rhizome powder.

A cotton bag loaded with $200 \mathrm{~g}$ of powdered ginger was poured in the extraction vessel (Figure 1). In total, nine experiments were conducted with varying optimization parameters including pressure $(10000-20000 \mathrm{kPa})$, temperature $\left(30-40^{\circ} \mathrm{C}\right)$ and $\mathrm{CO}_{2}$ flow rate $(5-20 \mathrm{~g} / \mathrm{min}$.). A 90 minute extraction time was kept constant for each experiment. At the end of each batch of experiments, a sample of ginger oleoresin extract was collected by opening the valve of the product collector vessel. The final yield of oleoresin was calculated on a percent weight basis and samples were stored in a refrigerator until analysis.

\subsection{HPLC analysis}

Ginger extracts collected from all optimization experiments using SC- $\mathrm{CO}_{2}$ and soxhlet extraction methods were analyzed quantitatively by using High Performance Liquid Chromatography (HPLC). Before analysis, prepared samples and standards were filtered through $0.45 \mu \mathrm{m}$ Nylon-66 membrane syringe filters (mdi Membrane Technologies LLC, California, USA). HPLC system (Waters 600) connected to a photo diode array detector (Waters 2998), quaternary pump, inline degasser and empower software was used. Reverse phase ODS $\mathrm{C}_{18}(4.6 \times 250 \mathrm{~mm})$ with $5 \mu \mathrm{m}$ particle size was used for [6]-gingerol analysis. The following solvent system was used for [6]-gingerol analysis:

Mobile phase A: Water and B: Acetonitrile was used in gradient mode as: A/B (60/40) for 1 min., A/B (20/80) for 2 to 8 mins., $A / B$ (5/95) for 9 to 10 mins. and finally hold for 3 mins. The total run time was programmed for 20 mins. at a flow rate of $0.5 \mathrm{~mL} / \mathrm{min}$. A chromatogram was recorded at $282 \mathrm{~nm}$.

\section{4 nalysis of total phenol, flavonoid and antioxidant activity}

A very useful spectrophotometric method of analysis was applied for the measurement of total phenol, flavonoid and DPPH antioxidant activity in ginger oleoresin extracts. A UV-visible spectrophotometer (Shimadzu, UV-2600, Kyoto, Japan) was used for recording absorbance at 765 $\mathrm{nm}$ (total phenol), $415 \mathrm{~nm}$ (total flavonoid) and $515 \mathrm{~nm}$ 


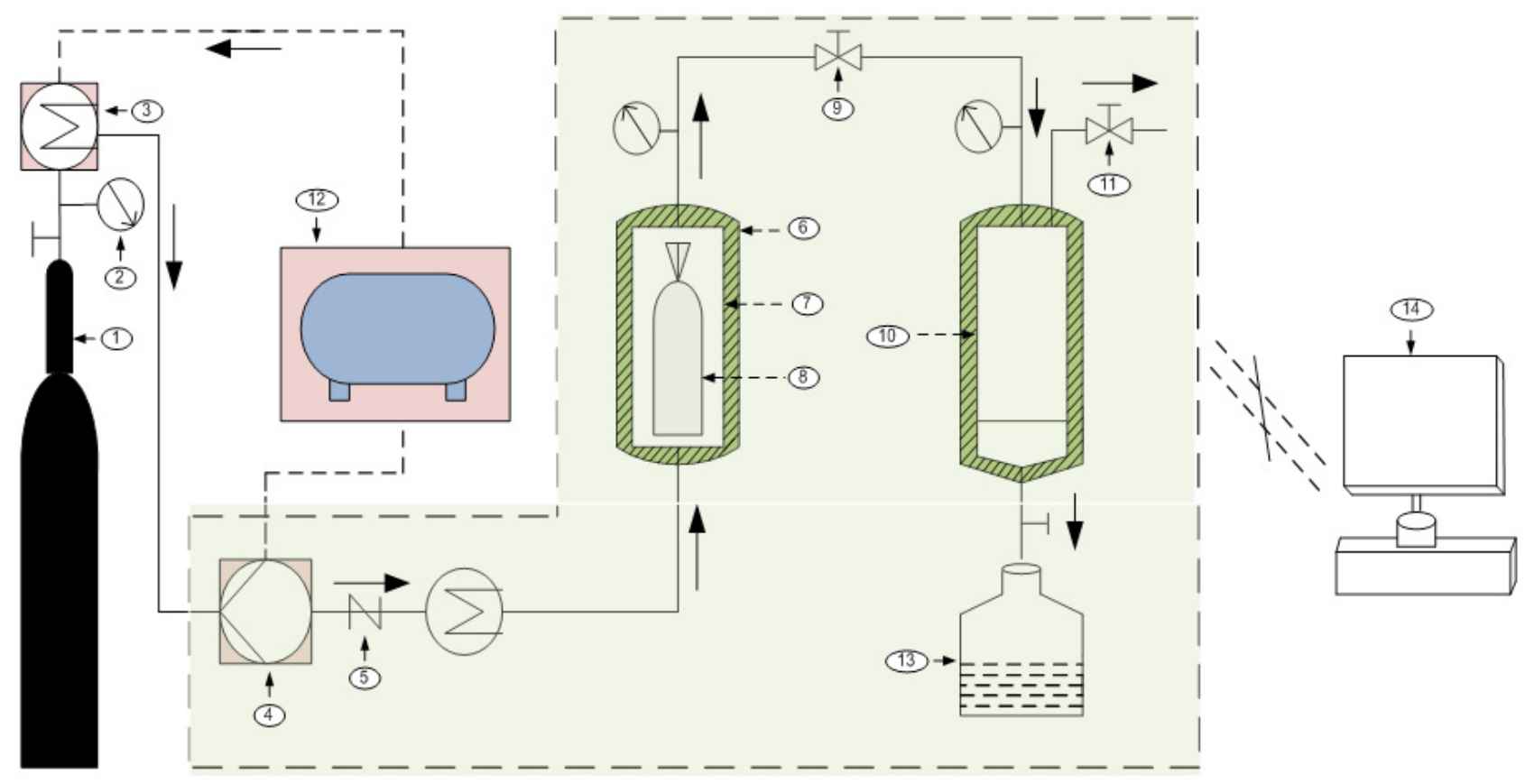

Figure 1: Schematic diagram of lab based supercritical $\mathrm{CO}_{2}$ extraction unit controlled by automation program

1. $\mathrm{CO}_{2}$ cylinder, 2. Flow meter, 3. Heat exchanger, 4. $\mathrm{CO}_{2}$ pump, 5. Non-returning valve, 6. Cooling/Heating jacket, 7. Extractor, 8. Raw material bag, 9. Automated Back Pressure Regulator (ABPR), 10. Product collector, 11. Manual ABPR, 12. Chiller, 13. Sampling bottle, 14. Programmable Logic Control (PLC) based operating system

(DPPH antioxidant activity). To measure the concentration of total phenols (TPC) and flavonoids (TFC), a standard calibration curve was plotted against the standards gallic acid (GAE) and quercetin (QE), respectively. Phenols and flavonoids results were expressed as $\mathrm{mg} \mathrm{GAE} / \mathrm{g}$ and $\mathrm{mg}$ $\mathrm{QE} / \mathrm{g}$, respectively.

In order to determine TPC, Folin-Ciocalteu method was used with some modifications in sample preparation. A sample extract/standard $(200 \mu \mathrm{L})$ was added to a test tube which already contained $1 \mathrm{~mL}$ freshly diluted (10 fold) Folin-Ciocalteu reagent. After eight minutes of incubation, $3 \mathrm{~mL}$ of $7.5 \%$ sodium carbonate solution was added to the mixture by manual shaking, and this was incubate for one hour at room temperature (Singleton and Rossi, 1965; Patel et al., 2015). In the case of TFC, a mixture of $400 \mu \mathrm{L} \mathrm{AlCl}_{3}(2.5 \%), 500 \mu \mathrm{L}$ sodium acetate $(10 \%)$ and $4 \mathrm{~mL}$ distilled water was added to $500 \mu \mathrm{L}$ of extract/ standard. After 15 minutes of incubation, absorbance was recorded (Hosu et al. 2014). Experimental procedures for measuring DPPH radical scavenging activity, the previously described method of Patel et al., (2015) was used for analysis. Sample results were expressed in terms of DPPH percent inhibition activity.

\subsection{Stability study of [6]-gingerol rich extracts}

The Rancimat-743 (Metrohm, AG Switzerland) instrument was used to measure the stability of [6]-gingerol rich extracts and other synthetic antioxidants in edible oils. Three edible oils (linseed, sunflower and peanut) extracted by using a mechanical screw press expeller were selected for the stability study. All required tubings and fittings of the Rancimat were set up by following the standard operational protocol describe int the Rancimat manual. Other experimental conditions including operating temperature $\left(110-130^{\circ} \mathrm{C}\right)$, concentration of antioxidants (100-300 ppm) and air flow rate $(20 \mathrm{~L} / \mathrm{h})$ was set according to the conditions described by Jaiswal et al., (2015). The results of the stability study were recorded as induction period (IP) in hours. The antioxidant indices of all three oils were calculated using the formula described by Jaiswal et al., (2015). All experiments for the stability study were repeated thrice in order to get the desired repeatability in results. 


\subsection{Statistical analysis}

The data generated by the stability study were analyzed statistically through the software SPSS v. 16.0 (SPSS Corporation, Chicago, IL). The results of the three replicates obtained were expressed in terms of mean \pm standard deviation and coefficient of variation (\%RSD). A simple $t$ test was applied to analyze data and significant differences recorded at $\mathrm{p} \leq 0.05$.

Ethical approval: The conducted research is not related to either human or animal use.

\section{Results and Discussion}

\subsection{Extraction yield}

\subsubsection{Solvent extraction yield}

Ginger powder samples stored in airtight plastic pouches were utilized for the extraction of oleoresin by using the soxhlet method of solvent extraction and food grade ethanol as an extraction solvent. The solvent miscible ginger oleoresin was concentrated in a rotary evaporator. Three extraction experiments were carried out to calculate the average extraction yield. The yield of ginger oleoresin was calculated as the ratio of ginger oleoresin obtained after extraction and weight of ginger powder sample taken prior to extraction. An average ginger oleoresin yield of $3.85 \pm 0.16 \%$ was obtained with a recovery of $75 \%$ ethanol in the rotary evaporator. The reason behind using ethanol as an extraction solvent was that ethanol is a more polar solvent, which is beneficial to extracting phenols and flavonoids from ginger. Previous researchers confirmed that the varying polarity of solvent significantly affect the yield of polyphenol content and antioxidant potential. They observed that more polar solvents have greater potential for extracting polyphenol content from plant material (Siddhuraju and Becker 2003; Sultana et al. 2007). Previously Ghasemzadeh et al.,(2011) carried out extraction of phenols and flavonoids from leaves, stems and the rhizome of two varieties of ginger species by using three different polarity solvents namely methanol, acetone and chloroform. The results of this study indicate that a high polarity solvent is more effective in the extraction of polyphenols and flavonoids from all plant parts of ginger. In a different study, Fidrianny et al. (2014) investigated the antioxidant capacities of three varieties of ginger, namely elephant ginger, small ginger and red ginger. All three varieties of gingers were extracted by using the increased polarity of a gradient solvent system (Hexane, ethyl acetate and ethanol). Antioxidant capacities of all three varieties extracted by the three solvents were correlated with phenolic, flavonoid and carotenoid contents of the ginger extracts. The results of this study revealed that changing polarity of solvents highly affected phenol, flavonoid and carotenoid content of ginger. Besides, ethanol was observed to be the best solvent in terms of extracting antioxidant compounds. The present study provides further support for the use of ethanol as an extraction solvent for getting antioxidant rich oleoresin extract from ginger powder. Apart from solvent polarity, the temperature of the extraction solvent also affects the chemical composition of the extracted ginger oleoresin. Gopi et al. (2016) carried out the extraction of ginger at different temperatures starting from 60 and ending at $120^{\circ} \mathrm{C}$. The result of that study revealed that above a temperature $90^{\circ} \mathrm{C}$, the active compound of gingerol is converted into its dehydrated product shogaol. In the present study, we carried out the extraction of ginger at a maximum temperature of $80^{\circ} \mathrm{C}$, which is highly unlikely to convert gingerol into shogaol.

\subsubsection{Supercritical extraction yield}

The yield of ginger extracts obtained during each optimization experiment of $\mathrm{SC}-\mathrm{CO}_{2}$ extraction is reported in Table 1. In total nine experiments under varying optimization conditions were performed in triplicates to calculate the average percent yield of ginger oleoresin. Extraction time in each experiment was kept constant (90 min.) and the yield of recovered oleoresin after each 30 min. time interval was added up to measure total oleoresin yield $(\mathrm{g})$ at the end of the experiment. In addition, the yield of oleoresin reported on a percent weight basis in Table 1 was calculated as total weight (g) of oleoresin obtained during each batch experiment divided by the mass of material (g) loaded into the extraction vessel for extraction.

Table 1 represents the abbreviated form of varying experimental conditions for nine $\mathrm{SC}-\mathrm{CO}_{2}$ experiments which were carried out in batch, and the resulting percent oleoresin and [6]-gingerol yields $(\mathrm{mg} / \mathrm{g})$. The first three experiments at pressure of $10000 \mathrm{kPa}$ with varying $\mathrm{CO}_{2}$ flow rates and temperatures resulted in percent oleoresin yields ranging from 0.51 to 1.17 . Moreover, the next six experiments, three each with a pressure of 15,000 and $20,000 \mathrm{kPa}$ resulted in percent oleoresin yields ranging from 1.17 to 1.46 and 1.69 to 2.41 , respectively. Oleoresin extract obtained after each optimization experiment was used for HPLC analysis investigating the yield of 
[6]-gingerol. Figure 2 (A) represents the chromatogram for [6]-gingerol standard while Figure 2 (B) represents the chromatogram obtained for crude ginger extract (obtained by SC- $\mathrm{CO}_{2}$ method) which contains [6]-gingerol with other chemical compounds. The yield of [6]-gingerol in the first three experiments at 10,000 kPa pressure resulted in [6]-gingerol content ranging from 75.24 to $108.58 \mathrm{mg} / \mathrm{g}$. It was observed that as the pressure increased from 15000 $\mathrm{kPa}$ to $20000 \mathrm{kPa}$ the content of [6]-gingerol in ginger extract also increased gradually. The content of [6]-gingerol in extract collected at a pressure of $15,000 \mathrm{kPa}$ ranging from 130.74 to $170.97 \mathrm{mg} / \mathrm{g}$. Moreover, in the next three experiments, using a pressure of $20,000 \mathrm{kPa}$ increasing [6]-gingerol content values ranging from 227.60 to 389 $\mathrm{mg} / \mathrm{g}$ were obtained. In the present study, experiments of $25,000 \mathrm{kPa}$ pressure with varying processing parameters were also performed to observe increasing yields of ginger extracts as well as [6]-gingerol content in extracts. But

Table 1: Yield of ginger oleoresin and [6]-gingerol obtained after Soxhlet and SC- $\mathrm{CO}_{2}$ extraction

\begin{tabular}{lllll}
\hline $\begin{array}{l}\text { Pressure } \\
(\mathbf{k P a})\end{array}$ & $\begin{array}{l}\text { CO2 Flow rate } \\
(\mathbf{g} / \mathbf{m i n} .)\end{array}$ & $\begin{array}{l}\text { Temperature } \\
\left({ }^{\circ} \mathrm{C}\right)\end{array}$ & $\begin{array}{l}\text { Oleoresin yield } \\
(\%)\end{array}$ & $\begin{array}{l}\text { [6]-gingerol yield } \\
(\mathbf{m g} / \mathbf{g})\end{array}$ \\
\hline 10000 & 5 & 30 & 0.51 & 75.24 \\
10000 & 10 & 35 & 0.93 & 98.35 \\
10000 & 20 & 40 & 1.17 & 108.58 \\
15000 & 5 & 30 & 1.42 & 130.74 \\
15000 & 10 & 35 & 1.44 & 142.06 \\
15000 & 20 & 40 & 1.61 & 170.97 \\
20000 & 5 & 30 & 1.69 & 227.60 \\
20000 & 10 & 35 & 1.88 & 252.73 \\
20000 (GE2) & 20 & 40 & 2.41 & 389.00 \\
Soxhlet (GE1) & - & - & 3.85 & 297.28 \\
\hline
\end{tabular}

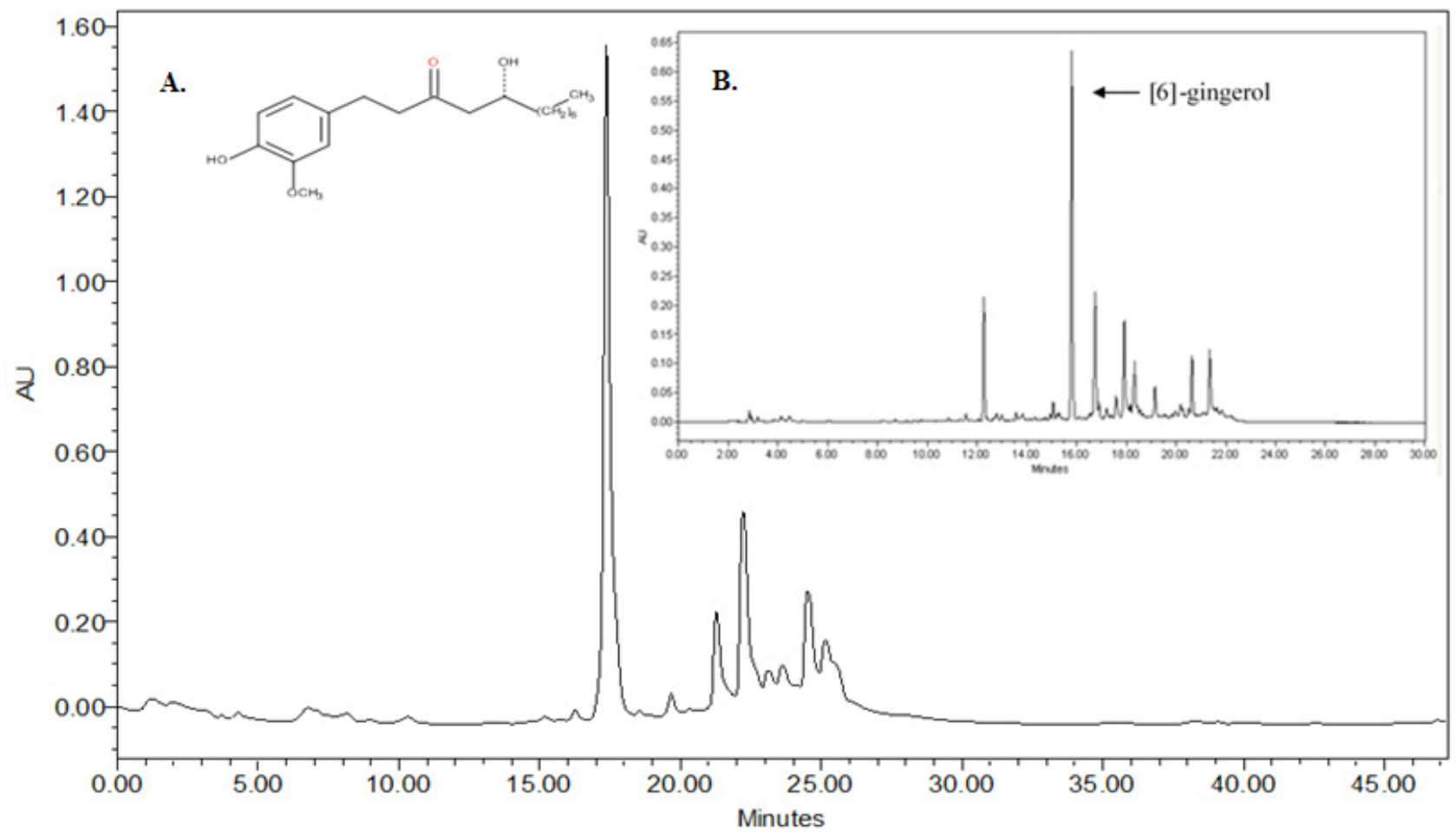

Figure 2: HPLC chromatogram for [6]-gingerol (A) [6]-gingerol standard (B) Ginger extract (GE2) 
no significant difference $(\mathrm{p}>0.05)$ was found in the yield of obtained ginger extracts, while the colour of ginger extracts changed from yellowish brown to dark brown because of the decreasing [6]-gingerol content. Analysis of ginger extracts obtained at 25,000 kPa pressure showed increasing concentrations of gingerol oxidation products like shogaol. The soxhlet method of solvent extraction produced [6]-gingerol content of up to $297.28 \mathrm{mg} / \mathrm{g}$ (GE1). Therefore, $\mathrm{SC}_{-} \mathrm{CO}_{2}$ extraction conditions of $20,000 \mathrm{kPa}$ pressure, $40^{\circ} \mathrm{C}$ temperature and $20 \mathrm{~g} / \mathrm{min}$. $\mathrm{CO}_{2}$ flow rate were considered to be the optimum conditions (GE2), with the highest yield of both oleoresin (2.41\%) and [6]-gingerol (389 mg/g).

In a very similar study, Puengphian and Sirichote (2008) carried out extraction of fresh ginger rhizomes at two varying extraction conditions (a) 20,000 $\mathrm{kPa}$ pressure and $35^{\circ} \mathrm{C}$ temperature, and (b) $23,000 \mathrm{kPa}$ pressure and $40^{\circ} \mathrm{C}$ temperature. The results of that study revealed that condition (a) produced higher [6]-gingerol content (238.94 $\mathrm{mg} / \mathrm{g}$ ) than condition $\mathrm{b}$ (170.50). In the present study, a pressure of $20,000 \mathrm{kPa}$ and temperature of $40^{\circ} \mathrm{C}$ (GE2) resulted in the highest recovery of [6]-gingerol $(389 \mathrm{mg} / \mathrm{g})$. This marked difference in [6]-gingerol values at a pressure of 20,000 $\mathrm{kPa}$ between the previous and present study may be due to different varieties of raw ginger sample, different flow rates of $\mathrm{CO}_{2}$ or differences in extraction temperature $\left(5^{\circ} \mathrm{C}\right)$.

Mesomo et al. (2012) in their study reported that a pressure of $25000 \mathrm{kPa}$, temperature of $20^{\circ} \mathrm{C}$ and extraction time of 180 minute is responsible for producing a $2.42 \%$ oleoresin yield, and the present study showed a similar approximate oleoresin yield (2.41\%) at optimum conditions (GE2). In the present study, $5000 \mathrm{kPa}$ less pressure (20000 $\mathrm{kPa}$ ) and less time (90 mins.) is responsible for the good recovery of oleoresin. This increased yield of oleoresin in the present study at lower extraction pressure and extraction time may be due to differences in ginger species or may be due to the use of higher extraction temperatures $\left(40^{\circ} \mathrm{C}\right)$ at the time of extraction.

In another study, it was reported that a pressure of $25,000 \mathrm{kPa}$, temperature of $40^{\circ} \mathrm{C}$, extraction time of 180 minutes and $15 \mathrm{~g} / \mathrm{min}$. $\mathrm{CO}_{2}$ flow rate are the optimum conditions for achieving maximum yield (6.87\%) of ginger oleoresin (Said et al. 2014). Based on all the literature above, it has been concluded that there are a several extraction conditions and extraction yields of oleoresin which depend on the type of extraction material used or extraction time extended for a particular extraction condition or extraction conditions (pressure, temperature and $\mathrm{CO}_{2}$ flow rate) used to get particular chemical compounds from raw ginger powder.
Salea et al. (2017) carried out the extraction of [6]-gingerol from ginger by using the supercritical fluid extraction method in laboratory and at a commercial scale. Pressure, temperature and solvent flow rate were optimized at the time of extraction to achieve better recovery of [6]-gingerol. The [6]-gingerol yield was obtained at optimized conditions of 15,000 kPa pressure, temperature of $35^{\circ} \mathrm{C}$ and a flow rate of $15 \mathrm{~g} / \mathrm{min} . \mathrm{CO}_{2}$ was compared with the solvent extracted ( $n$-hexane) ginger extract. The ginger extract yield obtained by using the supercritical method was observed to be 3.10\% (Laboratory scale) and 3.83\% (Commercial scale) while solvent extracted ginger resulted in higher yields (5.3\%) due to the presence of residual solvent in the extract. In terms of [6]-gingerol, the supercritical extraction method produced values ranging from $18-20 \%$, while the solvent extraction method produced poor levels of [6]-gingerol content $(4.59 \%)$. The findings by the present study in terms of ginger extract yield and [6]-gingerol content obtained by both supercritical and solvent extraction method is consistent with the trend of result reported by Salea et al., (2017).

\subsection{Total phenol, flavonoid and antioxidant study}

Total phenolic and flavonoid content of selected ginger extracts obtained by the supercritical (GE2) and soxhlet (GE1) method are shown in Figure 3. The values of TPC and TFC for all extracts were measured against gallic acid (GAE) and quercetin (QE) standard, respectively. The TPC value for GE1 (38.50 $\pm 0.96 \mathrm{mg} \mathrm{GAE} / \mathrm{g}$ ) was recorded to be more than for GE2 $(21.10 \pm 0.62 \mathrm{mg} \mathrm{GAE} / \mathrm{g})$. On the other hand, the same trend of results was observed in the case of total flavonoids, where values of GE1 $(5.62 \pm 0.37 \mathrm{mg} \mathrm{QE} / \mathrm{g})$ were again slightly higher than that of GE2 $(4.78 \pm 0.11 \mathrm{mg}$ $\mathrm{QE} / \mathrm{g})$. Comparing phenol and flavonoid content in both the extraction methods, values of phenols were recorded to be higher than flavonoid content. Overall, ginger oleoresin extract obtained by the soxhlet method was found to be richer in phenols and flavonoids compared to the ginger oleoresin extract obtained by the supercritical method.

Ghasemzadeh et al. (2011) measured TPC and TFC of ginger rhizome extracts extracted by different solvents namely, methanol, acetone and chloroform. The results of TPC and TFC in all three solvents ranged from 9.2 to $13.4 \mathrm{mg}$ $\mathrm{GAE} / \mathrm{g}$ and 3.23 to $4.70 \mathrm{mg} \mathrm{QE} / \mathrm{g}$, respectively. The trend of results presented here for TPC and TFC is in agreement with the previous study and also produced better values for all 
solvent and supercritical ginger extracts. Solvent polarity plays an important role in the extraction of phenol and flavonoid compounds from plant matrices. Ghasemzadeh et al. (2011) observed higher TPC and TFC values in the polar solvent methanol than in acetone and chloroform. In a similar study, increased polarity of methanol $(80 \%)$ by adding water was used for extraction of ginger oleoresin. This extracted ginger oleoresin produced increased TPC values of $42 \mathrm{mg} \mathrm{GAE} / \mathrm{g}$ (Turgay and Esen 2015). Stoilova et al. (2007) observed the highest phenol content of up to $870.1 \mathrm{mg} \mathrm{GAE} / \mathrm{g}$ for ginger extracts when using the $\mathrm{SC}-\mathrm{CO}_{2}$ extraction method. This marked difference in TPC values may be due to differences in varieties of raw ginger, or different extraction parameters. Karadag et al. (2009) discussed in detail different results in antioxidant activity of the same type of food due to differences in variety, extraction conditions, sample preparation methods, different antioxidant measuring standards and different concentration of antioxidant compounds. All these parameters greatly affect the final yield of antioxidant compounds and their antioxidant activities.

The antioxidant activity of selected ginger extracts (GE1 and GE2) was evaluated by using the DPPH method. The results of the DPPH assay were expressed in terms of percent inhibition activity as shown in Figure 3. For GE1 and GE2, readings of percent inhibition activities were taken in triplicates at three different concentrations (500, 1500 and $3000 \mu \mathrm{g} / \mathrm{mL})$. At $500 \mu \mathrm{g} / \mathrm{mL}$ concentration, GE1

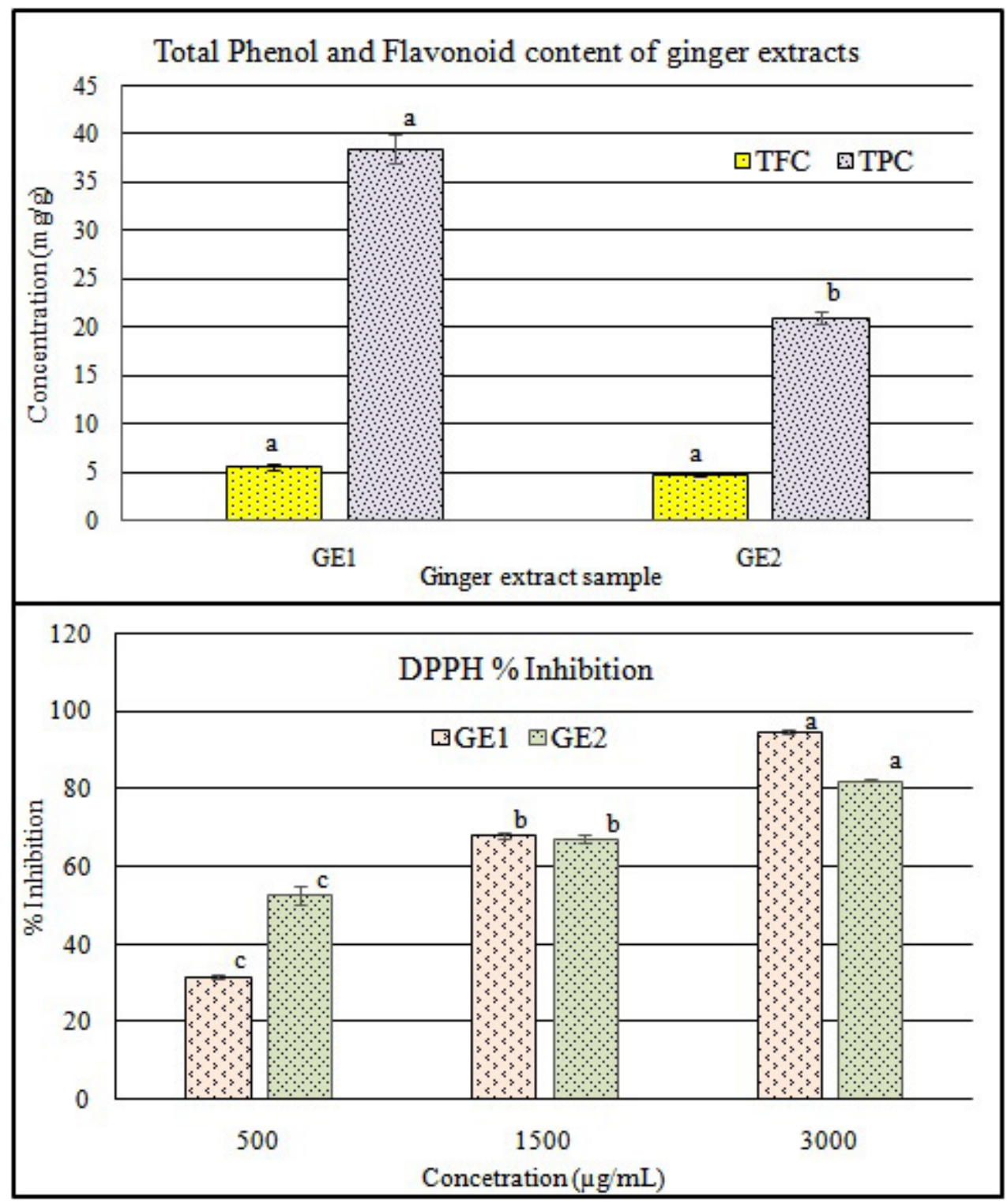

Figure 3: TPC, TFC and DPPH \% inhibition activity of ginger extracts extracted by soxhlet (GE1) and SC-CO ${ }_{2}(\mathrm{GE} 2)$ method. Different letters on bars indicates significant difference $(p<0.05)$ while same letters on bars indicates no significant difference 
and GE2 extracts produced $31.65 \pm 0.47$ and $52.82 \pm 2.24$ percent inhibition activity, respectively. As the concentration increased $(1,500 \mu \mathrm{g} / \mathrm{mL})$, percent inhibition activity was found to be increased equally in both extracts GE1 (68.39 \pm 0.79$)$ and GE2 (67.22 \pm 1.13$)$. But, after increasing concentration up to $3000 \mu \mathrm{g} / \mathrm{mL}$, the percent inhibition activity of GE1 produced higher $(94.85 \pm 0.56)$ percent inhibition activity than GE2 $(82.34 \pm 0.24)$. Total phenol and flavonoid content values of ginger extracts in both the supercritical and soxhlet method were found to be directly proportional to the values of DPPH percent inhibition. The extracts from the soxhlet method greater in phenol, flavonoid and DPPH percent inhibition than those from the supercritical method. Different studies on ginger carried out by different researcher's show different results in terms of antioxidant activity and total phenol content. All these varying results strongly depend on the type of extraction methods (solvent or modern extraction methods) and parameters (pressure, temperature and solvent flow rate), differences in ginger variety (according to country) and type of ginger (fresh or dried) subjected to extraction. Stoilova et al. (2007) carried out an extraction of Vietnam variety ginger by using the $\mathrm{SC}-\mathrm{CO}_{2}$ extraction method. After extraction, he carried out a total phenol and antioxidant study of the ginger oleoresin extracts. The results of that study showed that ginger oleoresin extracts obtained had higher DPPH radical scavenging antioxidant activity (90.1\%) which may be due to the greatertotal phenol content ( $870.1 \mathrm{mg} \mathrm{GAE} / \mathrm{g}$ ) found in oleoresin extracts. In another study, El-Ghorab et al. (2010) compared extracts of fresh and dried ginger by using polar (methanol) and non-polar (Hexane) solvents to measure phenol content and antioxidant activity. Fresh ginger proved to be richer in total phenols than dried ginger, while the recovery of phenolic compounds was greater in methanol extracts than hexane extracts. In terms of antioxidant activity, both methanol and hexane extracts of ginger produced the same trend of result as observed with the total phenol method. Again methanol extracts (concentration $240 \mu \mathrm{g} / \mathrm{mL}$ ) of both fresh (87.66\%) and dried (84.11\%) ginger produced more DPPH percent inhibition activity over hexane extracts of the same $(82.41 \%$, $80.45 \%)$. From this study, it can be concluded that polar solvents have more potential for recovering phenolic and antioxidant compounds from ginger rhizome. Moreover, fresh ginger has been found to be richer in phenol than dried ginger. Gupta et al. (2014) also measured the DPPH percent inhibition activity of methanol extract of ginger which was found to be up to $84.18 \%$. In the present study, the $\mathrm{SC}-\mathrm{CO}_{2}$ extract of ginger (GE2) produced DPPH percent inhibition activity in the range above $80 \%$ and observed percent inhibition value nearer to the values reported by El-Ghorab et al. (2010) and Gupta et al., (2014). In addition, the ethanol extract (GE1) of ginger obtained from soxhlet produced the highest DPPH percent inhibition activity (above 90\%) and was found to be more than previously reported.

\subsection{Stability study}

The stability of GE1 and GE2 extracts of ginger were tested in three edible oils by using the Rancimat method. Other synthetic antioxidants namely BHA, BHT and TBHQ were also tested in the Rancimat in comparison with GE1 and GE2. The results of the stability study for all selected antioxidants were calculated as antioxidant indices and are presented in Table 2 . Three edible oils namely linseed, sunflower and pea nut were chosen for the stability study according to their degree of unsaturation starting from higher (linseed oil) to lower (pea nut oil). Mechanically pressed fresh oil free from additives was used for the experiment.

Figure 4 (A) shows the graphical representation of the effect of different oils on the antioxidant index. The bar chart plots the antioxidant index values of three oils at a temperature of $110^{\circ} \mathrm{C}$ and $300 \mathrm{ppm}$ antioxidant concentration. Similar results were obtained for other temperatures $\left(120\right.$ and $\left.130^{\circ} \mathrm{C}\right)$ and antioxidant concentrations (100 and 200 ppm). From Figure 4 (A) it is cleared that the antioxidant index shows a descending trend of oil stabilization starting from highly unsaturated oil (linseed) to lower unsaturated oil (pea nut). In relation to both synthetic and natural antioxidants tested in the three oils, linseed oil was found to be more stable compared to the other two. TBHQ shows the highest antioxidant index in all three oils, preserving them effectively. From Figure 4 (A), it can be seen that antioxidant index values of GE1 and GE2 in linseed oil measured $2.92 \pm 0.24$ and $2.07 \pm 0.13$, respectively, while in sunflower oil, these values were lower at 1.12 \pm 0.04 (GE1) and 1.11 \pm 0.04 (GE2), respectively. Pea nut oil produced a positive, but smaller antioxidant index for GE1 (1.09) and GE2 (1.24) compared to linseed oil. In all three oils GE1 and GE2 produced comparable results with BHA and BHT at the antioxidant concentration of $300 \mathrm{ppm}$.

Figure 4 (B) displays the result of changing antioxidant index of pea nut oil with changing concentration of antioxidant index. Similar results were obtained for the other two oils. The results displayed in Figure 4(B) are considered only for the understanding of different scenarios in relation to the antioxidant index of oil with 


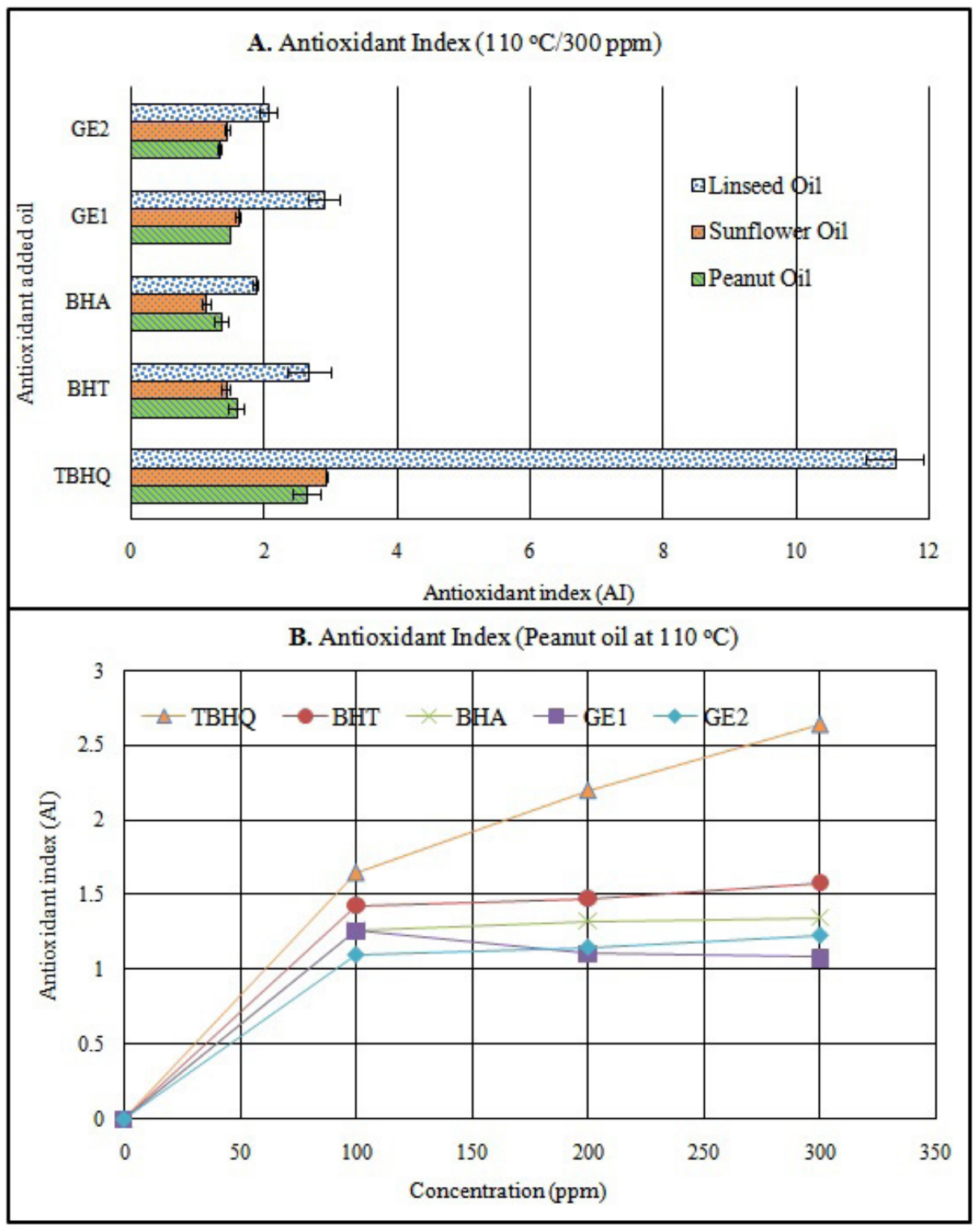

Figure 4: (A) Effect of changing oil on antioxidant index, (B) Effect of changing concentration of antioxidants on antioxidant index

changing concentrations of added antioxidants. All readings of pea nut oil antioxidant index after adding different antioxidants were recorded at $110^{\circ} \mathrm{C}$. The results of this study revealed that as the concentration of antioxidants in oil increased from 100-300 ppm the antioxidant index value of pea nut oil increased. The increasing trend of the pea nut oil antioxidant index at a condition of $110^{\circ} \mathrm{C}$ temperature and, $300 \mathrm{ppm}$ antioxidant concentration is: GE1 (1.08)<GE2 (1.24)<BHA (1.35)<BHT (1.58)<TBHQ (2.64). GE1 and GE2 produced good and comparatively similar antioxidant indices to BHA and BHT but were outperformed by TBHQ. Moreover, GE1 and GE2 were found to be effective in extending the oxidation period of all three oils. Detailed information about the effect of increasing temperature and concentration of antioxidant in all three oils is shown in Table2. All reported antioxidant indices in Table 2 are the means of triplicate determinations. In addition to this, the relative standard deviation (RSD) for each single experiment was also calculated to know the effectiveness of the antioxidant in oil. Lower values of RSD indicate that adding antioxidant to oil was more effective in stabilizing that oil.

Shadyro et al., (2017) carried outs stabilization study of linseed (flaxseed) oil by using synthetic (BHT, TBHQ, Agidol-2, PG) and natural antioxidants (tocopherols, ascorbyl palmitateand ascorbyl stearate). The stabilization effects of these selected antioxidants were also studied in different vegetable oils in order to determine their effectiveness on the basis of unsaturation the degree of oil. The result of that study indicate that fat soluble derivatives 
Table 2: Effect of temperature and antioxidant concentrations on antioxidant index and stability of oil

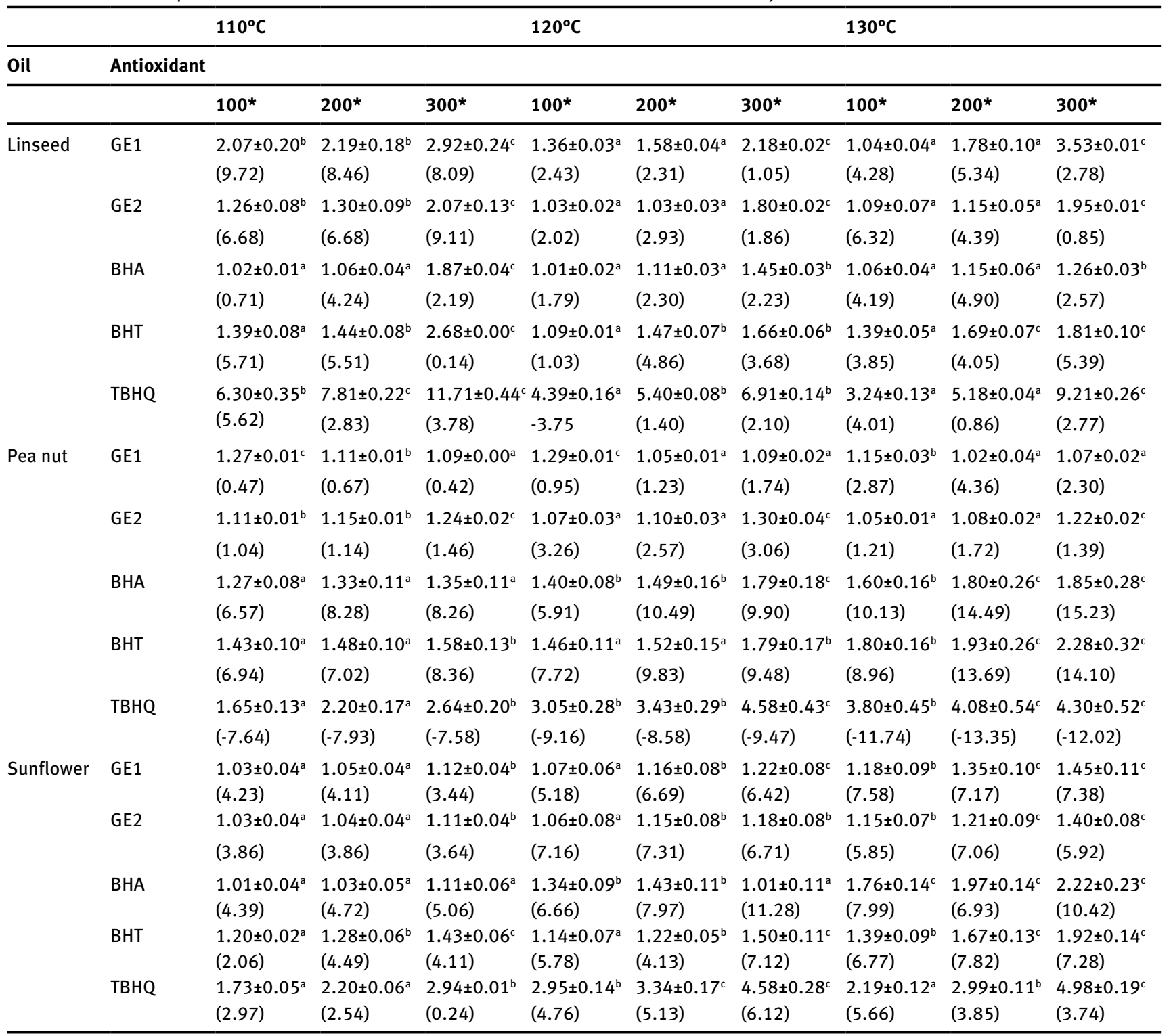

All values are expressed as antioxidant index \pm standard deviation, $(n=3)$ and coefficient of variation (\% RSD); * concentration in ppm.

${ }^{a-c} M e a n s$ in the same rows having different letters shows significant difference $(p \leq 0.05)$.

of ascorbic acid namely ascorbyl palmitate and ascorbyl stearate effectively protect flaxseed oil from oxidation and produce comparatively better stability results than the synthetic antioxidants BHT and PG. Alone asorbyl palmitate showed higher degree of stabilizing efficacy in linseed oil (higher unsaturation degree) than other investigated vegetable oils (lower unsaturation degree). The result of the present study in relation to linseed oil stabilization (with GE1 and GE2) followed by sunflower and peanut oil (based on oil unsaturation degree) is consistant with the previous study. Moreover, present ginger extracts (GE1 and GE2) obtained by both extraction methods produced comparable results with BHA and BHT at lower antioxidant concentrations reported previously. The results from present stability study for GE1 and GE2 in three different oils shows the scope for studying them for stabilization of unsaturated oil. Use of higher GE1 and GE2 concentrations (more than $500 \mathrm{ppm}$ ) to stabilize unsaturated oils in order to get comparable results with TBHQ, further highlights future study directions based on the present findings.

\section{Conclusion}

In conclusion, [6]-gingerol rich extracts (GE2) obtained by the $\mathrm{SC}-\mathrm{CO}_{2}$ extraction method produced comparable 
results with ginger extracts (GE1) from the soxhlet method. In the $\mathrm{SC}-\mathrm{CO}_{2}$ method, a pressure of $20,000 \mathrm{kPa}$, temperature of $40^{\circ} \mathrm{C}$ and $\mathrm{CO}_{2}$ flow rate of $20 \mathrm{~g} / \mathrm{min}$. were found to provide optimum conditions for maximum yield of ginger extracts of up to $2.41 \%$. The soxhlet method produced a higher extract yield (3.85\%), while the $\mathrm{SC}_{-} \mathrm{CO}_{2}$ method yielded higher [6]-gingerol content $(389 \mathrm{mg} / \mathrm{g}$ ) in extracts obtained under optimum conditions. On the other hand, GE1 produced higher TPC and TFC values than GE2. The concentration of total phenols (GE1-38.50; GE2-21.10 mg GAE/g) was significantly $(\mathrm{p}<0.05)$ greater than that of total flavonoids (GE1-5.62; GE2-4.78 mg QE/g) in both GE1 and GE2. Moreover, DPPH percent inhibition activity of both GE1 and GE2 at varying concentrations was also found to be significantly different. The stability study result of extracts GE1 and GE2 in three selected oils achieved positive antioxidant indices. Moreover, GE1 and GE2 were found to be suitable for stabilizing the more unsaturated linseed oil, followed by sunflower oil. The antioxidant indices of GE1 and GE2 were comparable with BHA and BHT, but the synthetic antioxidant TBHQ was found to be the most effective in stabilizing the three oils tested. Therefore, the $\mathrm{SC}-\mathrm{CO}_{2}$ extraction method may be the most promising alternative for recovering solvent free [6]-gingerol rich extracts for various food and pharmaceutical applications. Use of these [6]-gingerol rich extracts in stabilizing edible oils also provides reliable alternatives over synthetic antioxidants. However, a review carried out for the present study didn't show any evidence that [6]-gingerol rich extracts are not a safe alternative for stabilizing edible oils.

Acknowledgements: The present study was supported by MOFPI New Delhi, India. The first author acknowledges support from CSIR New Delhi, India for providing a PostDoctoral Fellowship [Grant No. 09/086(1268)/2017-EMR-I].

Conflict of interest: Authors state no conflict of interest.

\section{References}

Anonymous, The Wealth of India - A dictionary of Indian raw materials and industrial products, Publication Information Directorate, CSIR, New Delhi, 1976, XI (X-Z), 89-106

Anonymous, Ginger: Its role in xenobiotic metabolism. ICMR Bulletin, 2003, 33(6), 57-63

Butt M.S., Sultan M.T., Ginger and its health claims: Molecular aspects. Crit. Rev. Food Sci. Nutr., 2011, 51, 383-393

El-Ghorab A.H., Nauman M., Anjum F.M., Hussain S., Nadeem M., A comparative study on chemical composition and antioxidant activity of ginger (Zingiber officinale) and cumin (Cuminum cyminum). J Agric. Food Chem., 2010, 58, 8231-8237
Fidrianny I., Alvina A., Sukrasno, Antioxidant capacities from different polarities extracts of three kinds ginger using DPPH, FRAP assays and correlation with phenolic, flavonoid, carotenoid content. Int. J. Pharm. Pharm. Sci., 2014, 6, 521-525

Ghasemzadeh A., Jaafar H.Z.E., Rahmat A., Effects of solvent type on phenolics and flavonoids content and antioxidant activities in two varieties of young ginger (Zingiber officinale Roscoe) extracts. J Med. Plant Res., 2011, 5, 1147-1154

Gomez M., Lopez C.P., Martinez De La Ossa E., Recovery of grape seed oil by liquid and supercritical $\mathrm{CO}_{2}$ extraction: $\mathrm{A}$ comparison with conventional solvent extraction. Chem. Eng. J. Biocem. Eng. J., 1996, 61, 227-231

Gopi S., Varma K., Jude S., Study on temperature dependent conversion of active components of ginger. Int. J. Pharma Sci., 2016, 6, 1344-1347

Gupta R.K., Chawla P., Tripathi M., Shukla A.K., Pandey A., Synergistic antioxidant activity of tea with ginger, black pepper and tulsi. Int. J Pharm. Pharm. Sci., 2014, 6, 477-479

Hosu A., Cristea V., Cimpoiu C., Analysis of total phenolic, flavonoids, anthocyanins and tannins content in Romanian red wines: Prediction of antioxidant activities and classification of wines using artificial neural networks. Food Chem., 2014, 150, 113-118

Ito N., Hiroze M., Fukushima G., Tauda H., Shira T., Tatematsu M., Studies on antioxidants, their carcinogenic and modifying effects on chemical carcinogenesis. Food Chem. Toxicol., 1986, 24, 1071-1081

Jaiswal S.G., Pradhan S., Patel M., Naik M., Naik S.N., Rice bran oil distillate, a choice for $\gamma$-oryzanol: Separation and oxidative stability study. J. Food Res., 2015, 4, 36-43

Karadag A., Ozcelik B., Saner S., Review of methods to determine antioxidant capacities. Food Anal. Method., 2009, 2, 41-60

Kumolu-Johnson C.A., Ndimele P.E., Antioxidative and antifungal effects of fresh ginger (Zingiber officinale) treatment on the shelf life of hot-smoked catfish (Clariasgariepinus, Burchell, 1822). Asian J. Biol. Sci., 2011, Doi: 10.3923/ajbs.2011

Maizura M., Aminah A., Wan Aida W.M., Antioxidant capacity and consumer acceptability of herbal egg tofu. LWT - Food Sci. Technol., 2016, 65, 549-556

Martin A.D., Gilbert D., Enzyme changes accompanying liverenlargement in rats treated with 3-tert-butyl-4-hydroxyanisole. Biochem. J., 1968, 106, 22-27

Mesomo M.C., Corazza M.L., Ndiaye P.M., Santa O.R.D., Cardozo L., Scheer A., Supercritical $\mathrm{CO}_{2}$ extracts and essential oil of ginger (Zingiber officinale R.): Chemical composition and antibacterial activity. J. Supercrit. Fluids, 2013, 80, 44-49

Mesomo M.C., Scheer A., Perez E., Ndiaye P.M., Corazza M.L., Ginger (Zingiber officinale R.) extracts obtained using supercritical $\mathrm{CO}_{2}$ and compressed propane: Kinetics and antioxidant activity evaluation. J. Supercrit. Fluids, 2012, 71, 102-109

Patel M., Jaiswal S., Naik B., Naik M., Saxena D., Naik S. N., Development of antioxidant rich beverage from mahua (Madhuca indica) and amla (Emblica officinalis). J. Sci. Ind. Res., 2015, 75, 35-39

Puengphian C., Sirichote A., [6]-gingerol content and bioactive properties of ginger(Zingiber officinale Roscoe) extracts from supercritical $\mathrm{CO}_{2}$ extraction. As. J. Food Ag-Ind., 2008, 1, 29-36

Redondo-Cuevas L., Castellano G., Raikos V., Natural antioxidants from herbs and spices improve the oxidative stability and 
frying performance of vegetable oils. Int. J. Food Sci. Tech., 2017, Doi:10.1111/ijfs.13526

Rehman Z., Salaria A.M., Habib F., Antioxidant activity of ginger extract in sunflower oil. J. Sci. Food Agric., 2003, 83, 624-629

Salea R., Veriansyah B., Tjandrawinata R.R., Optimization and scale up process for supercritical fluid extraction of ginger oil from Zingiber officinale var. Amarum. J. Supercrit. Fluids, 2017, 120, 285-294

Semwal R.B., Semwal D.K., Combrinck S., Viljoen A.M., Gingerols and Shogaols: Important nutraceutical principles from ginger. Phytochemistry, 2015, 117, 554-568

Said P.P., Arya O.P., Pradhan R.C., Singh R.S., Rai B.N., Separation of oleoresin from ginger rhizome powder using green processing technologies. J. Food Process Eng., 2014, Doi: 10.1111/ jfpe.12127

Shadyro O.I., Sosnovskaya A.A., Edimecheva I.P., Flaxseed oil stabilization using natural and synthetic antioxidants. Eur. J. Lipid Sci. Technol., 2017, 119, Doi: 10.1002/ejlt.201700079

Siddhuraju P., Becker K., Antioxidant properties of various extracts of total phenolic constituents from three different agro-climatic origins of drumstick tree (Moringa oleifera lam.) leaves. J. Agric. Food Chem., 2003, 51, 2144-2155
Singleton V.L., Rossi J.A., Colorimetry of total phenolics with phosphomolybdic-phosphotungstic acid reagents. Am. J. Enol. Vitic., 1965, 16, 144-153

Stoilova I., Krastanov A., Stoyanova A., Denev P., Gargova S., Antioxidant activity of a ginger extract (Zingiber officinale). Food Chem., 2007, 102, 764-770

Sultana B., Anwar F., Przybylski R., Antioxidant activity of phenolic components present in barks of barks of Azadirachta indica, Terminalia arjuna, Acacia nilotica, and Eugenia jambolana Lam. trees. Food Chem., 2007, 104, 1106-1114

Turgay O., Esen Y., Antioxidant, total phenolic and antimicrobial characteristics of some species. Bulg. J. Agric. Sci., 2015, 21, 498-503

Vardanega R., Pardo J.M., Meireles M.A.A., Adding value to agri-food residues by means of supercritical technology. J. Supercrit. Fluids, 2015, 96, 217-227

Zhang G.F., Yang Z.B., Wang Y., Yang W.R., Jiang S.Z., Gai G.S., Effects of ginger root (Zingiber officinale) processed to different particle sizes on growth performance, antioxidant status, and serum metabolites of broiler chickens. Poult. Sci., 2009, 88, 2159-2166 